\title{
INFLUENCIA DE LA FERMENTACIÓN LÁCTICA (ABONO BOKASHI) EN EL PRE-COMPOST PARA LA PRODUCCIÓN DE BIOGÁS Y BIOL EN BIODIGESTORES TIPO BATCH
}

\author{
INFLUENCE OF LACTIC FERMENTATION (BOKASHI FERTILIZER) IN THE \\ PRE-COMPOST FOR BIOGAS AND ORGANIC FERTILIZER PRODUCTION IN BATCH \\ DIGESTERS
}

${ }^{1}$ Allen Torres T., ${ }^{2}$ Lawrence Quipuzco U. y ${ }^{3}$ Víctor Meza C.

\begin{abstract}
Resumen
El trabajo de investigación titulado: "Influencia de la fermentación láctica (abono bokashi) en el pre-compost para la producción de biogás y biol en biodigestores tipo batch" surge como una alternativa de tratamiento previo a los sustratos antes de colocarlos en los biodigestores y de esta manera mejorar la calidad de los subproductos generados: biogás y biol. La investigación se inició en Agosto del 2012, empleándose reactores que simulan a un biodigestor del tipo batch para tres tratamientos. Para los tres tratamientos se usó el mismo sustrato que fue estiércol de vacuno. La variación entre los tres tratamientos consistió en el tratamiento previo a utilizar: el Tratamiento 1: se colocó el sustrato a los biodigestores sin tratamiento previo, el Tratamiento 2: se realizó un pre-compostaje al sustrato antes de colocar a los biodigestores, y el Tratamiento 3: se realizó un abono bokashi como tratamiento previo antes de su colocación a los biodigestores, con la variante que este abono se ha desarrollado con microorganismos benéficos los cuales actúan sobre el sustrato haciendo que el tratamiento sea más eficiente en menor tiempo. Esta investigación tenía como objetivo comparar entre los tres tratamientos la calidad y cantidad de biogás y la calidad de biol. Para la composición de biogás se obtuvo un promedio de $\mathrm{CH}_{4}$ de $50,7 \%$ para el Tratamiento 1 , un promedio de $52.6 \%$ para el Tratamiento 2 , y un promedio de $50.9 \%$ para el Tratamiento 3 . La mayor producción de biogás se obtuvo en el Tratamiento $3\left(0.2 \mathrm{~m}^{3} / \mathrm{Kg} \mathrm{SV}\right)$, en comparación con el Tratamiento $2\left(0.15 \mathrm{~m}^{3} / \mathrm{Kg} \mathrm{SV}\right)$ y con el Tratamiento $1\left(0.1 \mathrm{~m}^{3} / \mathrm{Kg} \mathrm{SV}\right)$.
\end{abstract}

Palabras claves: Abono bokashi, biodigestor, biogás, biol, microorganismos benéficos.

\section{Abstract}

The research study named "Influence of lactic fermentation (bokashi fertilizer) in the pre-compost for biogas and organic fertilizer production in batch digesters" approaches as a solution to treatment before placing solid wastes in the anaerobic reactors and there by improve the quality of the products generated: biogas and organic fertilizer. The research began in August 2012, using batch anaerobic reactors for three treatments. For the three treatments we used the same substrate was cow manure. The variation between the three treatments consisted of treatment before use: Treatment 1 was placed anaerobic reactors substrate without pretreatment, Treatment 2 was performed pre-composting to the substrate before placing the anaerobic reactor, and Treatment 3 was performed as pretreatment bokashi compost before placing the anaerobic reactor, bokashi was developed with beneficial microorganisms which act on the substrate by make treatment more efficient in less time. This research aimed to compare between the three treatments the quality and quantity of biogas as organic fertilizer. For biogas quality, Treatment 1 reached an average concentration of $50.7 \%$ of methane, Treatment 2 reached an average of $52.6 \%$ and Treatment 3 reached an average of 50.9\%. For biogas volume Treatment 3 obtained a production of $0.2 \mathrm{~m}^{3} / \mathrm{kg}$ VS, Treatment 2 obtained a production of $0.15 \mathrm{~m}^{3} / \mathrm{kg} \mathrm{VS}$, and Treatment 1 obtained a production of $0.1 \mathrm{~m}^{3} / \mathrm{kg}$ VS. The organic fertilizer obtained in Treatment 3 has higher concentration of macronutrients and fewer pathogens in compared to Treatment 2 and Treatment 1, making the organic fertilizer in the Treatment 3 the highest quality.

Key words: Bokashi, anaerobic reactor, biogas, organic fertilizer, beneficial microorganisms.

\section{Introducción}

Un biodigestor es un sistema natural que aprovecha la digestión anaerobia de las bacterias que habitan en un residuo, para transformar éste en dos subproductos: el biogás y el biol (CEPIS, 1996).

Las comunidades dedicadas a las actividades agropecuarias suelen ser propietarias de grandes terrenos de cultivos y cabezas de ganado y pueden, por tanto, aprovechar el estiércol y rastrojos de plantas (pajas, tallos, hojas caídas) para producir su propio combustible y un fertilizante natural mejorado (biol).

Actualmente, el estiércol de vacuno se introduce directamente al biodigestor haciendo que la degradación anaerobia sea más prolongada. Por otro lado, existe un tratamiento convencional que se realiza para degradar

${ }^{1}$ Igeniero Ambiental Egresado de la UNALM

${ }^{2}$ Universida Nacional Agraria La Molina, Lima, Perú. Email: lquipuzco@lamolina.edu.pe

${ }^{3}$ Universida Nacional Agraria La Molina, Lima, Perú. Email: vmeza@lamolina.edu.pe 
el rastrojo presente en el estiércol que consiste en un humedecimiento y aireación de la materia por un período de 2-3 semanas para luego introducir al biodigestor. Ante esta problemática, se presenta una alternativa como tratamiento previo al cargado a los biodigestores, los abonos tipo bokashi. Su eficacia está comprobada en la agricultura porque incorpora al suelo materia orgánica, y nutrientes esenciales como: nitrógeno, fósforo, potasio, calcio, magnesio, hierro, manganeso, zinc, cobre y boro.

El objetivo principal de este estudio es evaluar la influencia del abono bokashi como un tratamiento previo con el fin de mejorar la cantidad de biogás y calidad de biogás y biol dentro de un proceso de degradación anaeróbica en los biodigestores.

\section{Materiales y métodos}

La presente investigación se llevó a cabo dentro del campus de la Universidad Nacional Agraria La Molina en las instalaciones de los Laboratorios de Ingeniería Ambiental entre los meses de Agosto y Diciembre del 2012.

El diseño experimental fue un Diseño de Bloques Completos al Azar (DBCA) con tres tratamientos y tres repeticiones. Los tratamientos fueron los siguientes:

Tratamiento 1: Estiércol de vacuno fresco

Tratamiento 2: Pre-compostaje de estiércol de vacuno

Tratamiento 3: Bokashi de estiércol de vacuno

Para el ensayo se diseñó un biodigestor tipo batch de 60.56 litros de volumen líquido cargado con $5 \%$ de sólidos totales.

Como inóculo se utilizó purín de cerdo de la granja de cerdos de la UNALM. Se añadieron 6.056 litros de purín a cada biodigestor (10\% del volumen líquido).

Para realizar el Tratamiento 1 se acondicionó un bidón de plástico de 20 galones, con el fin de recolectar el estiércol proveniente del establo de UNALM. El Tratamiento 1 fue el tratamiento control.

Para el Tratamiento 2 se acondicionaron 3 bidones de plástico de 20 galones cada uno, con el fin de recolectar el estiércol proveniente del establo la UNALM. El precompostaje, consistió en la aireación y humedecimiento del estiércol de vacuno es decir realizado en condiciones aeróbicas por 37 días

Según APROLAB (2007), la materia orgánica se descompone a través de la actividad de los microorganismos (bacterias, hongos, etc.) que se van alimentando de ella. Pero para poder hacerlo necesitan oxígeno y agua. Sin estas condiciones el proceso se detiene o la materia orgánica se pudre (sin suficiente oxigeno) liberando malos olores. Se añadió entre $500 \mathrm{ml}$ y 1 litro de agua cada 2 o 3 días, la cual ayudó a mantener la humedad del estiércol.

Para utilizar los microorganismos benéficos en el abono bokashi primero debemos activarlos. La lista de ingredientes con las cantidades necesarias y la metodología a utilizar fueron comprobadas en investigaciones anteriores (Cárdenas, 2012).

Los materiales que se utilizaron para la elaboración de los microorganismos benéficos fueron:

- $10 \mathrm{~kg} \mathrm{Col} \mathrm{fresca}$

- 10 litros Agua hervida

- $1 \mathrm{Kg} \mathrm{Sal}$

- $3 \mathrm{Kg}$ Melaza

- $3 \mathrm{Kg}$ de hígado de res

Los ingredientes se mezclaron y se homogenizaron en un bidón de 20 galones.

El pH deseado dentro para la elaboración de los microorganismos benéficos debe ser menor de 4 , siendo sus niveles óptimos menores de 3.5.

El Tratamiento 3, el abono bokashi, consistió en el volteo del estiércol de vacuno para fomentar la aireación y el humedecimiento del mismo con solución de microorganismos benéficos preparado anteriormente. El abono bokashi elaborado fue realizado en condiciones aerobias durante 7 días.

El volteo se realizó con ayuda de una pala, removiendo el estiércol y homogenizándolo favoreciendo el ingreso de oxígeno. Para el humedecimiento se utilizó una botella de plástico y se vertió entre $500 \mathrm{ml}$ a 1 litro de la solución cada 2 o 3 días sobre el estiércol.

Luego de concluir con la elaboración de los tres tratamientos se procedió a la carga de los 9 biodigestores, así como al sellado y conexión de los gasómetros a los reactores para que se pueda ir almacenando el biogás producido.

El levantamiento de datos y toma de muestras fueron para los siguientes parámetros:

\section{pH}

Para realizar la medición del pH se utilizó un potenciómetro de campo del Laboratorio de Ingeniería Ambiental de la UNALM. La medición se realizó dos veces por semana por espacio de 9 semanas.

\section{Composición del biogás}

Para medir la composición del biogás se utilizó el equipo Monitor de Gas por Extracción, marca LANTEC, modelo GEM500, el cual nos muestra la composición porcentual de $\mathrm{CH}_{4}, \mathrm{CO}_{2}, \mathrm{O}_{2}$ y gases trazas en el biogás. Las mediciones se realizaron dos veces por semanas en un lapso de 9 semanas que duró la fase experimental.

\section{Temperatura}

La temperatura se midió con el equipo de Gas por Extracción, marca LANTEC, modelo GEM500, el cual tiene un sensor de temperatura. Las mediciones se realizaron dos veces por semanas durante un lapso de 9 semanas. Los datos de temperatura ambiental se 
obtuvieron de la UNALM, a través del observatorio Alexander Von Humboldt.

\section{Volumen de biogás}

Para la medición del volumen de biogás producido se tomó un sistema de medición elaborado en los Laboratorio de Ingeniería Ambiental, basado en el desplazamiento de volúmenes mediante el uso de flotadores. La medición se realizó una vez por semana en un lapso de 9 semanas.

\section{Composición química del biol}

Las muestras para el análisis de composición química del biol fueron colectadas en frascos de plástico de primer uso de 1 litro de capacidad. El análisis para biol se realizó en el Laboratorio de Análisis de Suelos, Plantas, Aguas y Fertilizantes (UNALM).

\section{Análisis microbiológico}

Los análisis microbiológicos que se realizaron fueron los de coliformes totales y coliformes fecales.

La toma de muestra para la composición química y el análisis microbiológico se realizaron al final de las 9 semanas de la parte experimental.

Para la validación estadística de los datos se utilizaron el coeficiente de variabilidad (CV), análisis de varianza (ANVA) y la prueba de Tukey, la cual permite evaluar la significancia de todas las diferencias entre tratamientos, tomando un nivel de significancia del $5 \%$.

\section{Resultados y discusión}

La Tabla 1 muestra el resultado del análisis de conteo de microorganismos benéficos. Se aprecia una gran cantidad de bacterias anaerobias, mohos, levaduras y acido lácticas. Esto asegura que nuestro bokashi tendrá una gran concentración de microorganismos que actuará en gran cantidad degradando el sustrato más rápido.

Tabla 1. Resultados del conteo de microorganismos benéficos.

\begin{tabular}{lc}
\hline \multicolumn{1}{c}{ Análisis Microbiológico } & Número \\
\hline Recuento de mohos (UFC/g) & $24 \times 10^{5}$ \\
Recuento de bactérias ácido láctico (UFC/g) & $54 \times 10^{4}$ \\
Recuento de anaeróbios (UFC/g) & $90 \times 10^{5}$ \\
\hline
\end{tabular}

En la Figura 1 se aprecia cómo el Tratamiento 1 inicia con un valor de $\mathrm{pH}$ menor que los demás tratamientos. Para el caso del Tratamiento 2, el estiércol de vacuno fue sometido a un pre-compostaje, donde el $\mathrm{pH}$ disminuye por la formación de ácidos orgánicos por la acción de microorganismos sobre los carbohidratos, lo que favorece la descomposición de la celulosa y lignina. Este periodo corresponde a la etapa mesófila del compostaje. Lo siguiente es un aumento de $\mathrm{pH}$ por la formación de amoniaco debido a la desaminación de las proteínas, correspondiente a la etapa termófila del compostaje.
En el caso del Tratamiento 3, la finalidad del bokashi es la eliminación de malos olores y microorganismos patógenos, por ello al agregar los microorganismos benéficos anteriormente activados en un $\mathrm{pH}$ ácido actúan sobre el sustrato haciendo que el valor de $\mathrm{pH}$ de éste disminuya. En el caso del Tratamiento 1 y 2 se observa este aumento del $\mathrm{pH}$ después de un descenso en las primeras tres semanas. En el caso del Tratamiento 3 no se observa este descenso debido a que el sustrato al ser sometido a un tratamiento avanzado da como producto un material más degradado y estable.

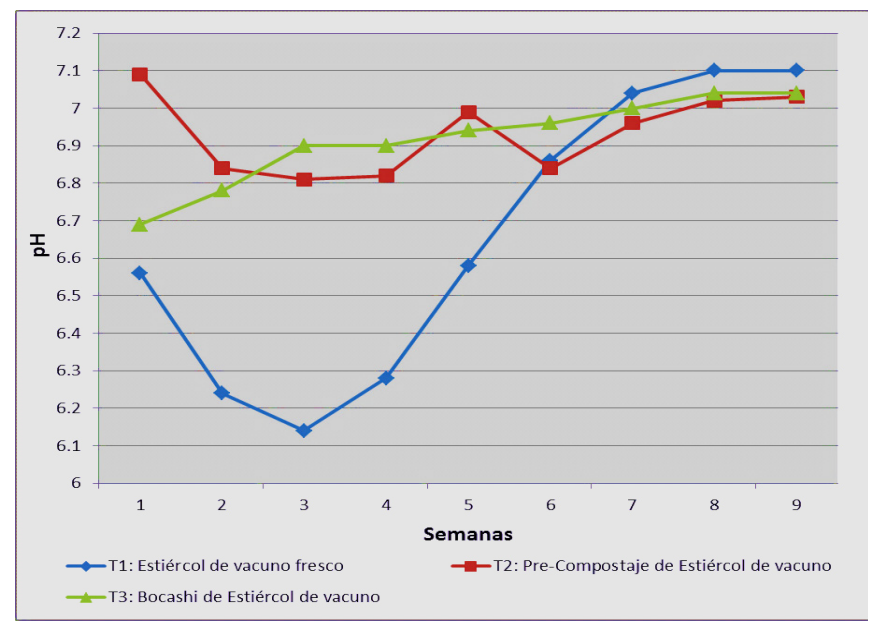

Figura 1.Comportamiento del $\mathrm{pH}$ durante la fase experimental.

Respecto a la temperatura promedio interna en los reactores: para el Tratamiento 1 fue de $26.5^{\circ} \mathrm{C}$, para el Tratamiento 2 fue de $26.9^{\circ} \mathrm{C}$ y para el Tratamiento 3 fue de $26.8^{\circ} \mathrm{C}$.

En la Figura 2, se puede apreciar el comportamiento porcentual del metano a lo largo de toda la fase experimental, donde desde un inicio se observa presencia de metano.

Para el caso del Tratamiento 1 se observa un aumento pausado en la concentración de metano producto de la lenta descomposición de la materia orgánica.

Para el caso de los Tratamientos 2 y 3 fueron sometidos a un pre-compostaje y bokashi respectivamente lo que hace que el sustrato sea más factible a ser degradado. Por ello, en ambos tratamientos existe una mayor degradación de la materia orgánica la que se vio reflejada en un aumento acelerado en la concentración de metano para ambos tratamientos.

En el Tratamiento 1 se tiene un valor máximo promedio de $50.7 \%$ de metano, el cual se logró en la sexta semana. Este valor supera ligeramente el valor mínimo (40\%) que debe contener el metano para que tenga las propiedades caloríficas necesarias para una buena combustión. Para el Tratamiento 2 se tiene un valor máximo promedio de $52.6 \%$ de metano, lo cual lo pone por encima del valor mínimo de concentración de metano en el biogás. 
Asimismo para el Tratamiento 3 se tiene un valor máximo promedio de $50.9 \%$ lo cual concluye en que los tres tratamientos superaron el valor mínimo de $40 \%$ en concentración de metano. Además se observa que el Tratamiento 2 y 3 llegan a sus máximos valores de metano en la quinta semana, mientras que el Tratamiento 1 a la sexta semana.

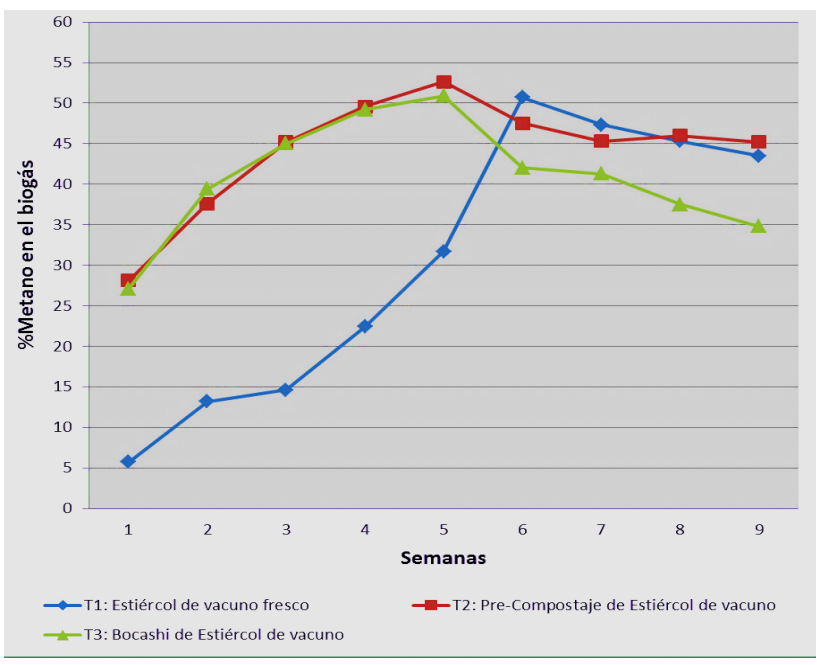

Figura 2.Comportamiento porcentual del metano durante la fase experimental.

En la Figura 3 se puede apreciar el volumen acumulado de biogás producido para los tres tratamientos, siendo mayor el producido por el Tratamiento 3 .

Se tiene que para el Tratamiento 1 se tiene un volumen acumulado de 276.4 litros, para el Tratamiento 2 un volumen acumulado de 445.8 litros y para el Tratamiento 3 un volumen acumulado de 657.7 litros.

Para poder calcular la producción de biogás en término de $\mathrm{m}^{3} / \mathrm{Kg} \mathrm{ST}$, se necesita saber la cantidad de sólidos totales presentes en el biodigestores. En este experimento se trabajó con un valor de 5\% que equivale a $3.028 \mathrm{~kg}$ de sólidos.

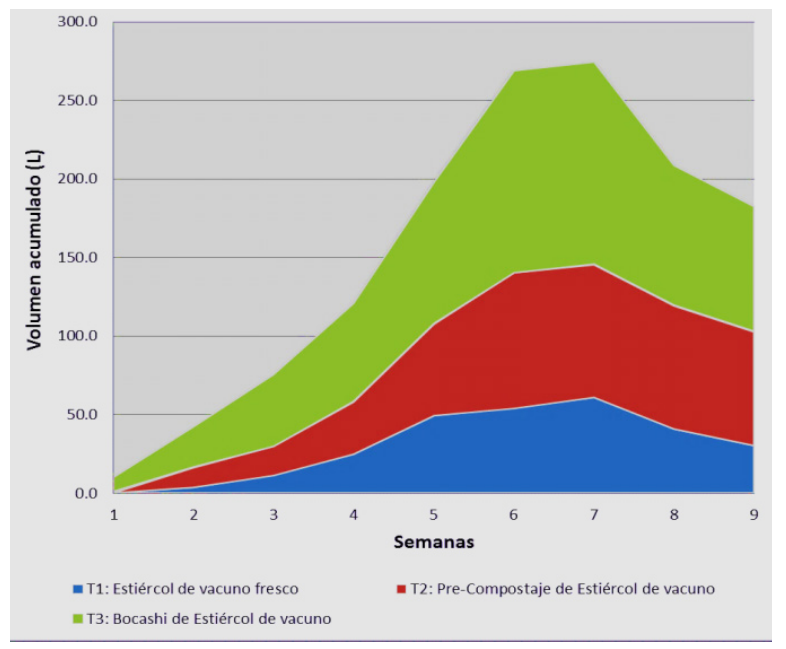

Figura 3. Volumen acumulado de biogás a Condiciones Normales.

Tabla 2. Comparación de la calidad de biol obtenido con otras investigaciones.

\begin{tabular}{|c|c|c|c|c|c|c|c|}
\hline \multirow{2}{*}{ Parámetros } & \multirow{2}{*}{ Unidad } & \multirow{2}{*}{$\begin{array}{l}\text { T1:Estiércel-de } \\
\text { yacung }\end{array}$} & \multirow{2}{*}{$\begin{array}{c}\text { T2: Pre- } \\
\text { Compostaje } \\
\text { deEstiércolde } \\
\text { xacung }\end{array}$} & \multirow{2}{*}{$\begin{array}{l}\text { T3:Bokashi } \\
\text { deEstiércol } \\
\text { dexacune }\end{array}$} & \multirow{2}{*}{ BACB (1) } & \multicolumn{2}{|c|}{ Cárdenas, 2012 (2) } \\
\hline & & & & & & EV & RO+E V \\
\hline $\mathrm{pH}$ & - & 7.16 & 7.15 & 7.14 & 7.30 & 6.78 & 6.69 \\
\hline C.E & $\mathrm{dS} / \mathrm{m}$ & 10.98 & 9.69 & 12.9 & 14.70 & 9.45 & 16.03 \\
\hline Sólides-Totales & $g 1$ & 27.87 & 22.76 & 34.26 & - & - & - \\
\hline $\begin{array}{l}\text { Matenia } \\
\text { Orgánica }\end{array}$ & g1 & 18.80 & 13.73 & 20.60 & 4.74 & 6.70 & 8.83 \\
\hline N-Total & $\mathrm{mg} /$ & 1323 & 1194.7 & 1551.7 & 920.0 & 676.67 & 81433 \\
\hline P-Total & $\mathrm{mg} /$ & 307.97 & 335.60 & 423.05 & 92.20 & 50.50 & 26.06 \\
\hline $\mathrm{K} \cdot$ Total & $\mathrm{mgl}$ & 12433 & 15942 & 1885.8 & 2297.50 & 75533 & 108333 \\
\hline Ca-Total & $\mathrm{mg}$ & 1157.5 & 649.17 & 1044.17 & 230.60 & 76533 & 177333 \\
\hline Mg-Total & $\mathrm{mg}$ & 301.67 & 270.83 & 334.17 & 15120 & 278.67 & 224.67 \\
\hline Na-Total & $\mathrm{mg} /$ & 610 & 510.83 & 81833 & 667.50 & 436.00 & 841.33 \\
\hline
\end{tabular}

(1) BACB: Biol de Agricultura Casa Blanca.

(2) Cárdenas, 2012: Evaluación de la calidad de biogás y biol en digestores utilizando estiércol de vaca y residuos orgánicos del comedor pretratados con la técnica del bokashi en la UNALM. 
En la Tabla 2 se puede apreciar los resultados promedio de los análisis químicos realizados a los bioles obtenidos y se compara con los valores obtenidos con el biol de Agricultura Casa Blanca (el cual está hecho a base de estiércol de cuy y de un sistema tipo batch, pues cuentan con un biodigestor tipo chino) y con el biol de Cárdenas (2012), en cuya investigación utilizó un sistema semicontinuo utilizando como sustrato para sus digestores estiércol de vaca (EV) y bokashi de residuos orgánicos mezclado con estiércol de vaca $(\mathrm{RO}+\mathrm{EV})$.

En la Tabla 3 se observa los valores promedios obtenidos con respecto a los organismos patógenos que se analizaron: coliformes totales, coliformes fecales y una comparación con la investigación realizada por Cárdenas (2012).

Tabla 3. Comparación de la calidad microbiológica del biol con otras Investigaciones.

\begin{tabular}{|c|c|c|c|c|c|c|}
\hline \multirow{2}{*}{ Parámetros } & \multirow{2}{*}{ Unidad } & \multirow{2}{*}{$\begin{array}{c}\text { Tl: Estiércol } \\
\text { de-vacuno } \\
\text { fresco }\end{array}$} & \multirow{2}{*}{$\begin{array}{l}\text { T2:-Pre- } \\
\text { Compostaje-de } \\
\text { estiércol-de } \\
\text { vacuno }\end{array}$} & \multirow{2}{*}{$\begin{array}{l}\text { T3: Bokashi } \\
\text { de estiércol-de } \\
\text { vacuno }\end{array}$} & \multicolumn{2}{|c|}{ Cárdenas, 2012} \\
\hline & & & & & $\mathbf{E V}(1)$ & $\mathbf{R O}+\mathbf{E V}(2)$ \\
\hline $\begin{array}{l}\text { Coliformes } \\
\text { totales }\end{array}$ & $\mathrm{NMP} / 100 \mathrm{ml}$ & $61.7 \times 10$ & $41.67 \times 10$ & $22.1 \times 10$ & $50 \times 10$ & 40 \\
\hline $\begin{array}{l}\text { Coliformes } \\
\text { fecales }\end{array}$ & $\mathrm{NMP} / 100 \mathrm{ml}$ & 13 & $24.7 \times 10$ & 10 & $50 \times 10$ & 40 \\
\hline
\end{tabular}

(1) EV: Estiércol de vaca.

(2) RO+EV: Bokashi de residuos orgánicos más estiércol de vaca.

Se observa que para el Tratamiento 1 el número de coliformes totales es casi equivalente al número de coliformes totales en el tratamiento EV (Estiércol de vaca) que presenta Cárdenas (2012). No obstante, el número de coliformes fecales para la presente investigación es menor.

Para el caso del Tratamiento 3 el número de coliformes totales es mayor que el Tratamiento RO+EV (Bokashi de residuos orgánicos más estiércol de vaca). Sin embargo el número de coliformes fecales para la presente investigación es menor que lo presentado por Cárdenas (2012).

Si bien es cierto, el proceso de biodigestión no eliminó totalmente a los organismos patógenos, los resultados obtenidos han permitido que se cumpla con los estándares para uso de agua para fines de riego en los coliformes fecales, obteniéndose un valor muy por debajo de los 1000 NMP/100 ml que establece el Estándar de Calidad Ambiental para Agua (D.S. 002-2008- MINAM). Para el caso de los coliformes totales el estándar establece un valor de $5000 \mathrm{NMP} / 100 \mathrm{ml}$ que al igual que el caso anterior se cumple para los tres tratamientos.

\section{Conclusiones}

La aplicación de una tecnología avanzada como es el abono bokashi para el tratamiento del estiércol de vacuno previa a la digestión anaerobia presenta ciertas ventajas en cuanto al tiempo de su elaboración y la influencia en la producción de biogás y biol respecto a la carencia de un tratamiento o realizar un tratamiento convencional.

Se ha determinado la influencia de la temperatura ambiental sobre la temperatura interna de los reactores, siempre manteniéndose la temperatura interna en $6.7^{\circ} \mathrm{C}$ mayor que la temperatura ambiental.

La mejor calidad de biogás se presenta en el Tratamiento 2 (52.6\%). El análisis estadístico nos muestra que hubo diferencia significativa respecto a los resultados del Tratamiento 1 (50.7\%). Por otro lado no hubo significancia entre el Tratamiento $3(50.9 \%)$ y el Tratamiento 1.

Para el caso del Tratamiento 2 y Tratamiento 3 el tiempo de retención en el cual se da la máxima producción de metano se da en la semana 5 de la fase experimental, mientras que el Tratamiento 1 lo consigue una semana después.

El volumen de biogás obtenido utilizando abono bokashi (Tratamiento 3) en términos de volumen acumulado equivale a 657.7 litros, éste volumen fue mayor que el producido al realizar el pre-compostaje (Tratamiento 2) que equivale a 445.8 litros de volumen acumulado y al volumen acumulado sin tratamiento previo (Tratamiento 1) que equivale a 276.4 litros.

La calidad del biol para el Tratamiento 3 presenta concentraciones más elevadas en macronutrientes en comparación al biol obtenido con los otros dos Tratamientos, esto se debe a la calidad del sustrato obtenido previo a la carga de los biodigestores y la influencia del abono bokashi sobre la calidad del biol.

\section{Agradecimientos}

Los autores agradecen al Departamento de Ingeniería Ambiental, Física y Meteorología de la Facultad de Ciencias de la UNALM por las facilidades para el 
desarrollo de la presente investigación en las instalaciones del Laboratorio de Ingeniería Ambiental.

\section{Literatura citada}

APROLAB (Programa de apoyo a la formación profesional para la inserción laboral en el Perú), 2007. Manual para elaboración de compost en el Perú.

Cárdenas, J. 2012. Evaluación de la calidad de biogás y biol en digestores utilizando estiércol de vaca y residuos orgánicos del comedor pre-tratados con la técnica del bocashi en la UNALM. Tesis.Universidad Nacional Agraria La Molina.

CEPIS, 1996. Fundamentos básicos para el diseño de biodigestores anaeróbicos rurales.

Decreto Supremo No 002-2008-MINAM Estándares Nacionales de Calidad Ambiental para Agua.

Earth, 2000. Bokashi (abono orgánico fermentado). Tecnología tradicional adaptada para una agricultura sostenible y un manejo de desechos modernos. San José. Costa rica.

GTZ, 2000. Producción de abonos orgánicos fermentados. Proyecto sanidad vegetal. Tegucigalpa.

Kiyan, T. 1999. Kyusei nature farming and the technology of effective microorganisms. Asia pacific natural agriculture network. Bangkok. Thailand. 